\title{
Epidermal cyst of temporal bone as a delayed complication of myringoplasty
}

\author{
MICHELE CAVALIERE* , ELENA CANTONE* ${ }^{*}$ STEFANIA SICIGNANO, \\ ANTONELLA MIRIAM DI LULLO and MAURIZIO IENGO
}

\begin{abstract}
Department of Neuroscience, Reproductive and Odontostomatologic Science, Ear, Nose and Throat Section, University of Naples 'Federico II', I-80131 Naples, Italy
\end{abstract}

Received November 10, 2016; Accepted February 14, 2017

DOI: $10.3892 /$ mco.2017.1267

\begin{abstract}
Epidermal cysts are benign tumors derived from the epidermis or the epithelial hair follicle filled with keratin and lipid-rich debris, typically occurring in areas with a highdensity of sebaceous glands. These cysts commonly occur on the face, scalp, neck and trunk, where the sebaceous glands are more active. Their localization within the bone is extremely uncommon. The current study details the case of a 24-year-old male who presented with right otorrhea and ipsilateral hypoacusia having undergone right overlay myringoplasty for subtotal eardrum perforation. This patient represents a rare case of an epidermal cyst localized in the temporal bone (the fifth described in English-language literature), which may be considered as a complication of myringoplasty.
\end{abstract}

\section{Introduction}

Epidermal cysts (EC) are benign subcutaneous or intradermal tumors derived from the epidermis or the epithelial hair follicle. They are formed from cystic enclosure of the epithelium within the dermis, and filled with keratin and lipid-rich debris. ECs commonly occur on the face, scalp, neck and trunk, where the sebaceous glands are more active; the localization within the bone is extremely uncommon, and the literature contains $\sim 70$ cases occurring in the distal phalanges of the fingers (1); and only 4 into the temporal bone (2-5).

Correspondence to: Dr Antonella Miriam Di Lullo, Department of Neuroscience, Reproductive and Odontostomatologic Sciences, Ear, Nose and Throat Section, University of Naples 'Federico II', Pansini Street 5, I-80131 Naples, Italy

E-mail: antonella.dilullo@libero.it

*Contributed equally

Abbreviations: EC, epidermal cysts; EAC, external auditory canal; $\mathrm{CT}$, computed tomography; MRI, magnetic resonance imaging

Key words: epidermal cyst, temporal bone, myringoplasty, complication
In the ear region ECs are typically identified in the posterior skin of the lobule or in the cartilaginous external auditory canal (EAC) and appear as soft masses indistinguishable from furuncles (2). Otomicroscopy may reveal signs of external otitis due to infection or thickening of the EAC. Clinical symptoms are otorrhea, pain and fullness, and conductive hearing loss is also common. Computed tomography (CT) and magnetic resonance imaging (MRI) aid diagnosis and planning of the therapeutic approach, of which surgery is the most accepted (2).

The current study presents, to the best of our knowledge, the first case of EC of the temporal bone following myringoplasty reported in the literature, focusing on its development and management and describing a suitable surgical technique to remove this type of lesion.

\section{Case presentation}

Informed consent was obtained from the patient for publication of this study. A 24-year-old male presented with right otorrhea and ipsilateral hypoacusia (May, 2016), having previously undergone right overlay myringoplasty for subtotal eardrum perforation (April, 2007) at the Ear Nose and Throat (ENT) Unit, University of Naples Federico II (Naples, Italy). The follow-up detected regular surgical outcomes until 9 years later, when by otomicroscopy an erosion of the EAC posterior wall was observed, with skin dislocated anteriorly and wax adherent to bone without impairment of the tympanic membrane. Although the patient did not report hypoacusia, audiometry revealed a right mild conductive hearing loss. A high-resolution CT scan of the temporal bone detected a nonhomogeneous low-density tissue eroding the nearby structures and surrounded by a bony capsule. MRI detected a high-intensity tissue in the right mastoid on T2-weighted images (Fig. 1).

The patient underwent surgical treatment. The surgical technique consisted of drilling the posterior wall of the external auditory canal to access the attached cyst (Fig. 2A). The cyst skin coating and wax within the pocket were removed and a section of temporalis fascia was placed over the cystic wall in order to facilitate re-epithelialization (Fig. 2B).

Finally meatoplasty was performed. As the tympanic membrane did not exhibit any perforation and the cyst was located laterally to it, the surgical procedure did not affect 

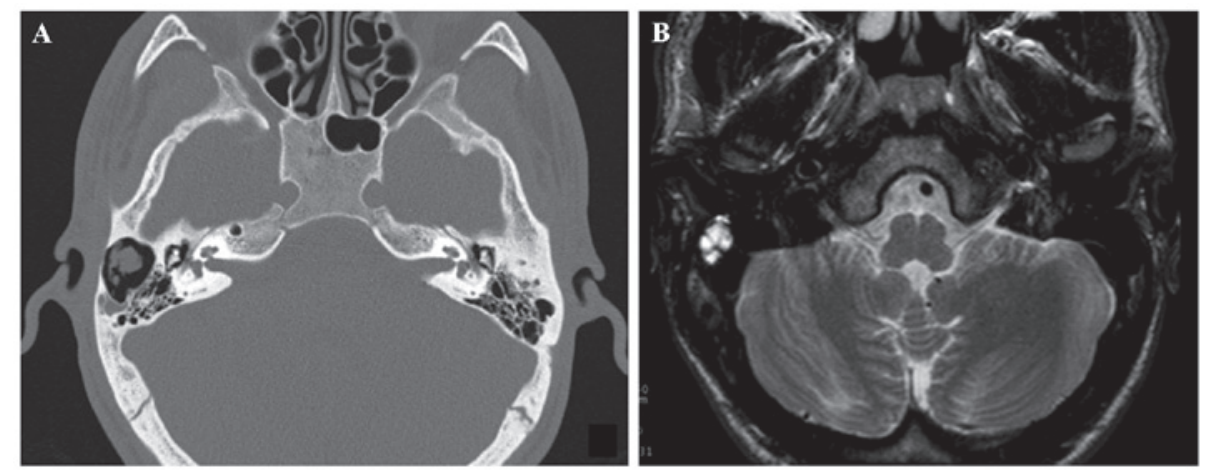

Figure 1. CT and MRI scan images of the patient. (A) High-resolution CT scan of the temporal bone revealed a non-homogeneous low-density tissue eroding the nearby structures, surrounded by a bony capsule. (B) MRI detected a high-intensity tissue in the right mastoid on T2-weighted images. CT, computed tomography; MRI, magnetic resonance imaging.
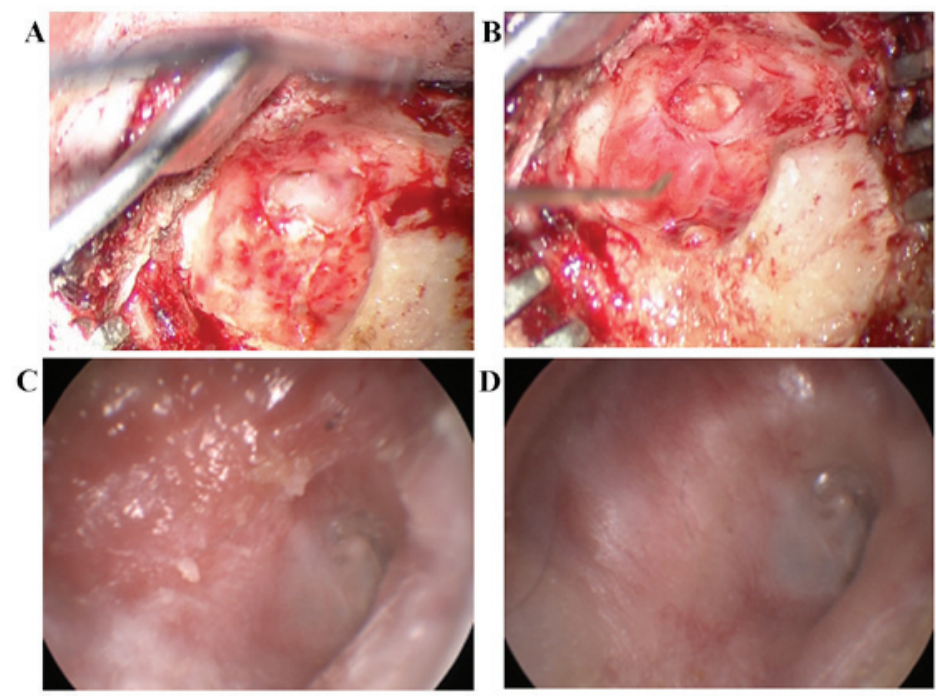

Figure 2. Surgical field and post-operative view. (A) Cyst attached to the external auditory canal; (B) positioning of temporalis fascia. Re-epithelialization was observed at (C) the one-month follow-up and (D) the three-month follow-up.

the middle ear. The histological evaluation confirmed the diagnosis of $\mathrm{EC}$ of the temporal bone. Epithelialization was effective at the 1- (Fig. 2C) and 3-month follow-up (Fig. 2D), and audiometry examination revealed improvement.

\section{Discussion}

Myringoplasty is a common surgical procedure; however, certain complications may occur, the most frequent of which are anterior membrane perforations or re-perforations during the underlay technique and the lateralization and/or blunting of the membrane in the overlay technique $(6,7)$. Irrespective of the surgical technique, a high degree of accuracy is required in the repositioning of the skin flaps (Fig. 3) (8). EC in the bone are extremely rare lesions ( $0.7 \%$ of cystic lesions) typically occurring in the distal phalanges of the fingers $(2,8)$. The current study is, to the best of our knowledge, the first case reported in the literature of temporal bone EC following overlay myringoplasty.

Two main pathophysiological hypotheses on the development of ECs exist; they may arise from the sequestration of epidermal rests during embryonic growth, or from the implan-

\section{IATROGENIC CHOLESTEATOMA}

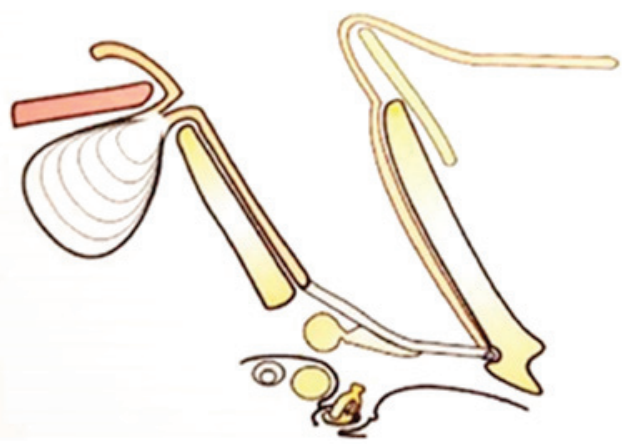

Figure 3. The formation of iatrogenic cholesteatoma, one of the most serious sequelae of myringoplasty. Iatrogenic cholesteatoma of the external auditory canal is generally caused by incorrect repositioning of the skin flaps. It is usually located in the anterior angle between the tympanic membrane and the anterior bony canal wall, but sometimes located posteriorly, eroding the posterior canal wall. From Sanna et al (8).

tation of mature epithelial elements in the bony tissue as a consequence of trauma, injury or surgery $(2,9)$. 
Due to the absence of components of the dermis, which are present in dermoid cysts, the present study does not support for the first hypothesis, whereas the second may be more likely. Indeed, the history of earlier trauma or surgery prior to the onset of the EC in the current case suggested the possible migration of epidermis into the site of the injury. Furthermore, to support the hypothesis of the implantation of mature epithelial elements, Zadek and Cohen (10) generated experimentally identical lesions by implantation of epidermis in bone tissue.

In the current case, the trauma during the myringoplasty was derived from the drilling of the bony EAC, where loci minoris resistentiae, such as tympanosquamous and tympanomastoid sutures, represented potentially suitable areas for the migration of epithelial components from the sub-optimally repositioned posterior meatal flap to the subperiostum. Over time, the epithelial components led to cystic cavity formation in the temporal bone.

In conclusion, for even simple surgical steps such as myringoplasty, care must be taken to avoid complications. Errors including poor repositioning of the skin flap may impact the outcome of procedure a number of years later. The patient in the current case remained free of symptoms. Occasionally during follow-up, a 'crack' in the external auditory canal was detected and radiological investigations were recommended. For this reason, it is important to consider the relevance of clinical and radiological follow-up in ear surgery.

\section{References}

1. Memon F, Panjwani TR and Patankar H: Intraosseous epidermoid inclusion cyst of distal phalanx: A rare entity. J Clin Diagn Res 10: RJ01-RJ02, 2016.

2. Yu WN, Fu SC and Lai JC: Epidermal cyst of the bony external auditory canal. Kaohsiung J Med Sci 29: 237-238, 2013.

3. de Gaudemar I, Elmaleh M, Cortez A, Peuchmaur M and François M: Unusual presentation of a first branchial cleft. Eur Arch Otorhinolaryngol 252: 57-60, 1995.

4. Suzuki T, Taki M, Shibata T, Matsunami T, Sakaguchi H, Yamamoto $\mathrm{S}$ and Hisa Y: Epidermal cyst of the bony external auditory canal. Otolaryngol Head Neck Surg 136: 155-156, 2007.

5. Alimoglu Y, Mercan H, Karaman E and Oz B: Epidermal inclusion cyst of external auditory canal. J Craniofac Surg 21: 1290-1291, 2010.

6. Sergi B, Galli J, De Corso E, Parrilla C and Paludetti G: Overlay versus underlay myringoplasty: Report of outcomes considering closure of perforation and hearing function. Acta Otorhinolaryngol Ital 31: 366-371, 2011.

7. Sarkar S: A review on the history of tympanoplasty. Indian J Otolaryngol Head Neck Surg 65 (Suppl 3): 455-460, 2013.

8. Sanna M, Sunose H, Mancini F, Russo A and Taibah AH: Middle ear and mastoid microsurgery. 2nd edition, Thieme, 2012.

9. Doğanavşargil B, Ayhan E, Argin M, Pehlivanoğlu B, Keçeci B, Sezak M, Basdemir G and Oztop F: Cystic bone lesions: Histopathological spectrum and diagnostic challenges. Turk Patoloji Derg 31: 95-103, 2015.

10. Zadek I and Cohen HG: Epidermoid cyst of the terminal phalanx of a finger; with a review of the literature. Am J Surg 85: 771-774, 1953. 